\title{
Investigation of a modified hydraulic calcium silicate-based material - Bio-C Pulpo
}

\author{
Lauter Eston PELEPENKO(a) \\ Flávia SAAVEDRA $^{(a)}$ iD \\ Thiago Bessa Marconato \\ ANTUNES(a) \\ Gabriela Fernanda BOMBARDA(a) \\ Brenda Paula Figueiredo de \\ Almeida GOMES(a) iD \\ Alexandre Augusto ZAIA(a) \\ Marina Angélica MARCIANO(a) \\ (a) Universidade Estadual de Campinas \\ - Unicamp, Piracicaba Dental School, \\ Department of Restorative Dentistry, \\ Piracicaba, SP, Brazil.
}

Declaration of Interests: The authors certify that they have no commercial or associative interest that represents a conflict of interest in connection with the manuscript.

Corresponding Author:

Lauter Eston Pelepenko

E-mail: lauterpelepenko@hotmail.com

Submitted: August 3, 2020

Accepted for publication: January 4, 2021

Last revision: February 18, 2021

\begin{abstract}
This study evaluated the physicochemical, biological, and antimicrobial properties of a new hydraulic calcium silicate-based modified material, and compared it with MTA Repair HP and MTA Angelus. The materials were assessed regarding color luminosity (L), color change, radiopacity, setting time, and ISO 6876:2012 linear flow. Volumetric filling and volume change were evaluated using microcomputed-tomography $(\mu \mathrm{CT})$. Chemical characterization after 28 days in Hank's Balanced Salt Solution (HBSS) and pH analysis were also assessed. Biological characterization of cytotoxicity and microbiological assessment were also undertaken. Shapiro-Wilk, ANOVA, Levene and post hoc analyses with Bonferroni correction were performed, adopting a $5 \%$ significance level $(\mathrm{p}<0.05)$. Bio-C Pulpo exhibited the highest $\mathrm{L}$ values after 90 days. All tested materials demonstrated color change during the analyses, and had radiopacity above $5 \mathrm{~mm}$ Al. MTA Repair HP set faster than Bio-C Pulpo, whereas the latter had the highest linear flow. MTA Repair HP had the highest volumetric filling in $\mu \mathrm{CT}$ analysis. Bio-C Pulpo showed the highest alkalinity during all tested periods, and the highest volumetric loss (above 9\%), in comparison with MTA Repair HP and MTA Angelus. Bio-C Pulpo did not form calcium hydroxide after hydration. MTA Repair HP demonstrated the highest cytocompatibility, and Bio-C Pulpo, the highest cytotoxicity. No inhibition halos were observed for any material, and similar higher turbidity values were seen after direct contact. Composition additives used in Bio-C Pulpo modified its properties, and both the absence of calcium hydroxide deposition after hydration, and the related cytotoxicity of this material are of particular concern.
\end{abstract}

Keywords: Endodontics; Dental Pulp Capping.

\section{Introduction}

Vital pulp therapy techniques and the use of adequate biomaterials can establish predictable, minimally invasive biological therapies with high success rates. Hydraulic calcium silicate cement is indicated to protect the dental pulp before definitive restoration. It is applied over the deep dentin when the pulp is not exposed, in indirect pulp capping procedures, or directly onto the exposed pulp, in direct pulp capping, or in partial or full pulpotomy. ${ }^{1,2}$ 
Materials used in vital pulp treatments should ideally possess physicochemical properties, such as flow and consistency that facilitate their insertion in cavities, short setting time to allow restoration in the same operative session, antimicrobial effect, and compatibility with adhesive systems or liners used before restorative procedures. Furthermore, these materials should be radiopaque, so that they can be visible in prospective clinical follow-ups, provide an alkaline environment, and deposit calcium hydroxide to induce the formation of dentin bridges, which potentially maintain pulp vitality after the application of these materials in definitive restorations. ${ }^{3,4}$ Calcium hydroxide deposition formed as a by-product of the hydration reaction of hydraulic calcium silicate-based materials is crucial, since it serves as a chemical mediator in tertiary dentinogenesis after vital pulp treatments. ${ }^{1,2,5}$

MTA Angelus (Angelus, Londrina, Brazil) is a hydraulic calcium silicate cement indicated for reparative endodontic procedures, and indirect and direct pulp capping. MTA Angelus is said to have poor handling, owing to its sandy consistency. ${ }^{6}$ This material was initially composed of tricalcium silicate (45-60\%), dicalcium silicate (5-12\%), tricalcium aluminate $(5-12 \%)$, tetracalcium aluminoferrite $(1-7 \%)$, calcium oxide (0-7\%), and bismuth oxide (15-30\%), as a radiopacifier. MTA Angelus powder hydration reaction uses distilled water, according to the manufacturer's instructions. Recently, the bismuth oxide was replaced with calcium tungstate. This modification of the formula avoids tooth discoloration, since bismuth oxide is responsible for dental discoloration. ${ }^{7}$ MTA Angelus has had success rates of $96 \%$ after 3-year follow-ups, when used as direct pulp capping or pulpotomy material in permanent mature teeth with carious exposure. ${ }^{8}$

MTA Repair HP (Angelus, Londrina, Paraná, Brazil) is a newer material developed by the same company. Its powder has a chemical composition similar to MTA Angelus, with calcium tungstate radiopacifier, but it incorporates polyvinylpyrrolidone (as a plasticizer), added to the distilled water used for material hydration, to enable better handling. MTA Repair HP has adequate physicochemical and biological properties with improved fluidity, in comparison with MTA Angelus. ${ }^{9}$
Regardless of the improvements, neither MTA Angelus nor MTA Repair HP are the ideal material for pulp capping procedures, because of their handling and interface interaction with restorative materials, as regards their hydraulic nature. ${ }^{4}$ Another aspect is their setting time, which usually must be extended during clinical procedures. ${ }^{10}$ Bio-C Pulpo (Angelus, Londrina, Paraná, Brazil) has recently been developed to offset these shortcomings of setting time and handling, properties that are required for a cement that has been developed as a pulp capping material, and that would allow the restorative procedure to be performed in the same session. The composition of its powder includes additives such as calcium hydroxide and silicon dioxide with zirconium oxide as a radiopacifier. Moreover, liquid additives, such as plasticizing material, calcium chloride and methylparaben, are added to the mixing water. ${ }^{11}$ These additives may interfere with cement hydration.

The present study aimed to evaluate the physicochemical, biological and antimicrobial properties of Bio-C Pulpo, compared to MTA Repair $\mathrm{HP}$ and MTA Angelus.

\section{Methodology}

\section{Preparation of the materials}

The materials were prepared according to the manufacturer's instructions (Angelus, Londrina, Brazil) for use in all the tests, as follows:

a. Bio-C Pulpo (Batch \#240419): one spoon with three drops of liquid spatulated for 40 seconds.

b. MTA Repair HP (Batch \#48081): one package of powder and two drops of the liquid spatulated for 40 seconds.

c. MTA Angelus (Batch \#45293 [powder] and \#45808 [liquid]): one spoon of MTA Angelus with one drop of distilled water spatulated for 30 seconds.

\section{Color stability in contact with dentin}

Stainfree bovine enamel-dentin tooth blocks $(10 \times 10 \mathrm{~mm})$ were prepared with a thickness standardized at $3.5 \pm 0.1 \mathrm{~mm}$, according to a previously reported method ${ }^{7}$. A cavity $5.0 \mathrm{~mm}$ in diameter and 1.5-mm deep was prepared at the center of the dentin 
surface, using a high-speed 4054 bur (Medical Burs Sorensen, São Paulo, Brazil). The specimens were then immersed in $1 \%$ sodium hypochlorite, washed, immersed in 20\% EDTA (pH 7.7) for 2 minutes (for dentin debris removal), irrigated with distilled water, and gauze-dried to simulate a dentinal disinfection procedure. Only the cavity edges were conditioned with $37 \%$ phosphoric acid for 30 seconds, and an adhesive layer (Adper Single Bond 2,3M ESPE, Sumaré, Brazil) was applied only to the conditioned edges, and light-cured for 20 seconds (Optilight LD Max, Gnatus, Ribeirão Preto, Brazil). The freshly mixed tested material was inserted into the cavities at a depth of $1.5 \mathrm{~mm}$. When the material reached its initial setting time, the cavity was sealed with a composite flow resin (B2, Nova DFL, Rio de Janeiro, Brazil) and light-cured for 60 seconds, after which the specimens were stored separately at $37^{\circ} \mathrm{C}$, in flasks containing $10 \mathrm{~mL}$ of distilled water, in which they were kept throughout the analysis period. Cavities were filled only with composite resin, and not with the cement; these were used as a negative control. Triple antibiotic paste (metronidazole, ciprofloxacin, and minocycline) in contact with dentin was used as a positive control.

A spectrophotometer (Vita EasyShade V, VITA Zahnfabrik, Bad Sackingen, Germany) set up in a light-controlled room was used to obtain the values of the International Commission on Illumination (CIE) 'L,' 'a,' and 'b.' The luminosity (L) assessment was performed before filling, and 24 hours, 28 days, and 90 days after filling. The values were recorded, and the color change $(\Delta \mathrm{E})$ was calculated considering $\mathrm{L}$ at 90 days, according to the following formula: $\Delta \mathrm{E}$ $=\left[\left(\mathrm{L}_{1}-\mathrm{L}_{0}\right)^{2}+\left(\mathrm{a}_{1}-\mathrm{a}_{0}\right)^{2}+\left(\mathrm{b}_{1}-\mathrm{b}_{0}\right)^{2}\right]^{1 / 2}$, where 0 represents the initial values before filling, and 1 represents the 90-day values.

After 90 days, representative specimens were sectioned and viewed under a stereomicroscope (SZX9, Olympus, Tokyo, Japan) at 2x magnification, and images were acquired using the AxioVision software program (Carl Zeiss, Jena, Germany). The sectioned samples were also prepared for scanning electron microscopy (SEM) (JSM 5600 Lv JEOL, Akishima, Tokyo, Japan) and energy-dispersive spectroscopy (EDS) to evaluate the ion migration of the material/ dentin interface.

\section{Radiopacity}

Radiopacity was evaluated according to the ISO 6876:2012 standard. Metal rings were used to shape the cement specimens $(10 \times 1 \mathrm{~mm})(\mathrm{n}=3)$. Samples were kept at $37 \pm 1^{\circ} \mathrm{C}$ and relative humidity until the final setting. The specimens were then removed from the rings and radiographed with a digital sensor (Micro Imagem, Indaiatuba, Sao Paulo, Brazil) as an alternative to avoid film processing effects, using the settings of $60 \mathrm{kV}, 10 \mathrm{~mA}, 0.3$-second exposure, and focus-film distance of $30 \mathrm{~cm}$., An aluminum scale of progressive thickness was used to compare the radiographic density, and the radiopacity of the samples was assessed and compared with this scale. Grayscale values obtained using the Image J software program (National Institutes of Health, Bethesda, MD, USA) were converted into aluminum equivalent thickness ( $\mathrm{mm} \mathrm{Al}$ ) using a previously reported formula. ${ }^{12}$

\section{Setting time}

Freshly mixed cement was placed into metal rings $(10 \times 2 \mathrm{~mm})(\mathrm{n}=3)$. The specimens were kept at a temperature of $37 \pm 1^{\circ} \mathrm{C}$ and humidity of $95 \pm 5 \%$ during the test, and periodically subjected to vertical pressure by using Gillmore needles (according to the ASTM-C266-18 standard) at room temperature controlled at $20 \pm 1^{\circ} \mathrm{C}$. A needle weighing $113.4 \mathrm{~g}$ was used to evaluate the initial setting time, and another weighing $453.6 \mathrm{~g}$, to evaluate the final setting time. The setting time was determined (in minutes) from when the mixing started until it was no longer possible to observe a complete round mark of each needle on the cement surface. ${ }^{12}$

\section{Flow}

Two different methods were used to perform the flow analysis in this study.

\section{Linear flow}

The ISO 6876:2012 standard was used for linear analysis. An aliquot of $0.05 \pm 0.005 \mathrm{~mL}$ of each cement $(n=3)$ dosed using a plastic syringe was placed at the center of a flat, smooth glass plate. After 3 minutes from the initial mixing, a glass plate weighing $20 \pm 0.5 \mathrm{~g}$ was positioned above the cement dose 
along with another 100-g weight. In 10 minutes, the mean between the highest and the lowest diameter was considered as the cement flow value (in $\mathrm{mm}$ ), measured by a digital caliper.

\section{Volumetric flow}

The volumetric flow was measured based on a linear and a three-dimensional cement flow in simulated grooves scanned using microcomputed tomography $(\mu \mathrm{CT}) .^{13}$ Grooved plates made of glass $(\mathrm{n}=5)$ were fabricated with a central cavity of $2 \mathrm{~mm}^{3}$ and four 12-mm lateral grooves. A dose of fresh material $(0.05 \pm 0.005 \mathrm{~mL})$ was placed in the central cavity. Afterwards, a glass plate $(20 \pm 0.5 \mathrm{~g})$ and an extra 100 -g weight were placed in the cavity for 10 minutes.

The linear lateral flow was measured linearly according to the amount of material in the lateral grooves, after weight was applied over the central cavity. The linear lateral flow average was obtained from the four lateral grooves measured in $\mathrm{mm}$. The volumetric flow was measured by analyzing the volume of the material in the central cavity and lateral grooves, using $\mu \mathrm{CT}$ (SkyScan 1174, Bruker, Kontich, Belgium) scans with a $0.5-\mathrm{mm}$ aluminum filter, $31.03-\mu \mathrm{m}$ pixel size, $360^{\circ}$ rotation, and 1.0-degree step. Raw images were reconstructed using the NRecon software program (Bruker, Kontich, Belgium), and the CTan software program (Bruker, Kontich, Belgium); the region-of-interest tool was used to perform the analysis. The lateral volumetric flow was represented by the average volume of the material in the four lateral grooves, 2-mm from the central cavity $\left(\mathrm{mm}^{3}\right)$. Central cavity filling was performed considering the volume of material in this region, in each grooved plate (in $\mathrm{mm}^{3}$ ), and the average was calculated for each tested cement.

\section{Analysis of $\mathbf{p H}$}

A previously reported method was used ${ }^{12}$ to perform the $\mathrm{pH}$ analysis. Acrylic teeth $(\mathrm{n}=5)$ with a standardized root-end cavity $(3 \times 1 \pm 0.1 \mathrm{~mm})$ were used. The cavities were filled with each freshly mixed tested material, and immersed in individual flasks containing $10 \mathrm{~mL}$ of deionized water. Experimental periods of 3 hours, 24 hours, and 28 days were evaluated, and samples were kept in a $37^{\circ} \mathrm{C}$ incubator during the entire analysis period. This range of time was used owing to the expected completion of the hydration reaction of tricalcium silicate-based materials in 28 days $^{14}$. A calibrated $\mathrm{pH}$-meter (Micronal 371 , Sao Paulo, Brazil) in a $20^{\circ} \mathrm{C}$ controlled temperature room was used to obtain the $\mathrm{pH}$ value corresponding to each period.

\section{Volume change}

Volume change was evaluated using a $\mu \mathrm{CT}$ scanner with an amount of material compatible with a surgical root-end cavity $(3 \times 1 \pm 0.1 \mathrm{~mm})$, as previously reported ${ }^{12}$. The cavities were filled with the cement $(\mathrm{n}=3)$, and the initial $\mu \mathrm{CT}$ scanning was performed according to the same parameters used for the flow analysis of the present study. Afterwards, each sample was immersed individually in a plastic flask containing $15 \mathrm{~mL}$ of deionized water and stored at $37^{\circ} \mathrm{C}$ for 28 days. After this period, the samples were dried gently with filter paper, and re-scanned using the same parameters. The re-scanned volume was compared with the initial ones, and the volume alterations were expressed in percentage.

\section{Chemical characterization}

X-ray diffraction (XRD), SEM, and EDS analysis were performed to determine the chemical characterization. Both un-hydrated and hydrated cement forms were evaluated using XRD. The un-hydrated cement powder was inserted directly into the sample holder for analysis. The hydrated cement was obtained by previously preparing the specimens $(15 \times 2 \mathrm{~mm})$, allowing them to set for 24 hours at $37^{\circ} \mathrm{C}$ in relative humidity of $95 \pm 5 \%$, immersing them in separate flasks containing $10 \mathrm{~mL}$ of Hank's Balanced Salt Solution (HBSS, Sigma-Aldrich Brazil, São Paulo, Brazil), and keeping them for 28 days at $37^{\circ} \mathrm{C}$. The HBSS solution was changed weekly. During the immersion period, the samples were dried, vacuum desiccated, and crushed into a fine powder using a mortar and pestle. The XRD-diffractometer (Bruker D8 Advance, Bruker, Billerica, MA, USA) was set at CuKa radiation, $40 \mathrm{~mA}$ and $45 \mathrm{kV}$. Rotation was set between $10-60^{\circ}$ with a 0.02 degree, $2 \theta$ step, and step time of 0.6 seconds. Phase identification of the material was undertaken using the 
search-match software program (Diffrac.Eva, Bruker Corp., Billerica, MA, USA) from the International Center for Diffraction Data (ICDD database, Newtown Square, PA, USA). Hydrated samples were epoxy resin-embedded, polished, and carbon-coated for the SEM (Zeiss Merlin Field Emission SEM, Carl Zeiss NTS GmbH, Oberkochen, Germany) and the EDS chemical analyses. SEM images of the microstructural components of the different materials were obtained in back-scatter electron mode, and the EDS of selected areas evaluated the chemical components present in each sample ${ }^{15}$ chemical, physical properties and porosity of experimental calcium silicate-based sealers. Methods Experimental calcium silicate-based sealers with calcium tungstate and zirconium oxide radio-opacifiers were prepared by mixing $1 \mathrm{~g}$ of powder to $0.3 \mathrm{~mL}$ of $80 \%$ distilled water and $20 \%$ propylene glycol. MTA and MTA Fillapex were used as controls. The raw materials and set sealers were characterized using a combination of scanning electron microscopy, energy dispersive spectroscopy and X-ray diffraction. Physical properties were analyzed according to ANSI/ADA. The $\mathrm{pH}$ and calcium ion release were assessed after 3, 24, 72 and $168 \mathrm{~h}$. The porosity was assessed using mercury intrusion porosimetry. Results The analysis of hydration of prototype sealers revealed calcium hydroxide as a by-product resulting in alkaline $\mathrm{pH}$ and detection of calcium ion release, with high values in initial periods. The radiopacity was similar to MTA for the sealers containing high amounts of radio-opacifiers $(\mathrm{p}>0.05$.

\section{Antimicrobial activity}

\section{Agar diffusion test}

Enterococcus faecalis (ATCC 29212) and Porphyromonas gingivalis (ATCC 49417) were used separately, and three sterile stainless-steel cylinders $(4.0 \times 1.0 \times 10 \mathrm{~mm}$; inner diameter of $6 \mathrm{~mm}$ ) filled with each freshly spatulated material were put in contact with the inoculated agar surface separately. An extra metallic disc containing only these liquid materials was also tested using filter-paper discs, because of the additive components present in MTA Repair HP and Bio-C Pulpo liquids. 2\% chlorhexidine gel impregnated in filter-paper discs was used as a negative control for bacterial growth. The plates were kept at room temperature for 30 minutes inside a laminar flow chamber, allowing initial setting of the cement before appropriate aerobic and anaerobic storage. Inhibition diameters of microbial growth were evaluated after incubation periods of 24 hours and 7 days for E. faecalis, and 48 hours and 5 days for $P$. gingivalis ${ }^{16}$ The test was repeated twice under the same conditions to confirm the results.

\section{Direct contact}

Bacterial suspension of $E$. faecalis in Brain Heart Infusion (BHI) broth was adjusted spectrophotometrically at $800 \mathrm{~nm}$ (Spectronic 20d+, Milton Roy, Houston, USA) to match the transmittance of $90 \mathrm{~T}$ (equivalent to $0.5 \mathrm{McF}$ arland scale $\left.=1.5 \times 10^{8}\right)^{16}$. Hydrated cement samples of $0.10 \mathrm{~g}$ were used after 24 hours of storage at $37^{\circ} \mathrm{C}$. The following sets were tested in triplicate: tubes 1, 2, and 3 containing the bacterial inoculum + cement sample; tube 4 containing the bacterial inoculum + felt paper disc impregnated with of $2 \%$ chlorhexidine gel (antimicrobial control); tube 5 containing the bacterial inoculum only (bacterial growth control); and tube 6 as blank BHI solution for spectrophotometer calibration purposes. Turbidity measurements were performed after the tubes were vortexed for five seconds: immediately, 3 hours, 24 hours, and 48 hours after contact with the tested materials. Simultaneously with the spectrophotometer readings, growth viability was checked by dripping $10 \mu \mathrm{L}$ broth aliquots of each tube separately on BHI plates stored at $37^{\circ} \mathrm{C}$, corresponding to each period for analysis after 24 hours. Cement dissolution was performed separately in tubes containing similar $0.10 \mathrm{~g}$ cement samples, in BHI without bacterial inoculum. The dissolution turbidity values obtained from these parallel tubes were subtracted from the expressed results.

\section{Cytotoxicity - Methylthiazolyldiphenyl-tetr azolium bromide (MTT)}

Cytotoxicity was assessed in primary human periodontal ligament fibroblasts harvested from the periodontal ligament of surgically removed third molars (B041 - Periocells of Periodontics Division of the Piracicaba Dental School, Brazil - Approved by the 
Research Ethics Committee of the Piracicaba Dental School [Ethics code: CAAE 20189119.7.0000.5418]). MTT assay was performed after 24 hours of direct contact between the materials and the fibroblasts. The wells of 24-well plates were used, and each material $(n=5)$ was placed individually in contact with the fibroblast culture. The absorbance reading was measured at $490 \mathrm{~nm}$, and the cell viability percentage, calculated by dividing the absorbance values of the experimental wells by those of the negative control group. Three independent experiments were carried out to ensure the reproducibility of the results. ${ }^{17}$

\section{Statistical analysis}

The JASP (University of Amsterdam, Amsterdam, The Netherlands), version 0.14 (2020) software program was used. The sample size was determined for each test to express a test power of at least $80 \%$. ANOVA was used, and the assumptions of this method, normal distribution and homogeneity of variances were validated through the Shapiro-Wilk and Levene tests. A post hoc analysis with Bonferroni correction was performed to check the differences between the groups, adopting a $5 \%$ significance level $(p<0.05)$.

\section{Results}

\section{Color stability in contact with dentin}

Average $L$ values at 24 hours, 28 days, and 90 days, and $\Delta \mathrm{E}$ between, before, and 90 days after filling are shown in Table 1. Representative images of the blocks, sectioned samples, SEM microphotographs, and EDS mapping overlaps are represented in Figure 1. Bio-C Pulpo exhibited higher L values than MTA Repair HP, and the negative control after 90 days $(p<0.05)$. All the tested materials showed $\Delta \mathrm{E}$ during the analysis period. During EDS analysis, phosphorus $(\mathrm{P})$ and zirconium (Zr) ions overlapped in the Bio-C Pulpo samples.

\section{Radiopacity, setting time, flow, analysis of $\mathrm{pH}$, volume change, and chemical characterization}

Radiopacity, setting time, and flow average values are shown in Table 2. Analysis of $\mathrm{pH}$ and volume change are shown in Table 3.

Bio-C Pulpo and MTA Angelus had similar radiopacity values $(p>0.05)$, and all the tested materials showed average radiopacity values above $5 \mathrm{~mm} \mathrm{Al}$, thereby meeting the minimum of $3 \mathrm{~mm} \mathrm{Al}$ required by the ISO 6876:2012 standard. MTA Repair HP had the fastest initial and final setting times, significantly different from Bio-C Pulpo ( $p<0.05)$. Bio-C Pulpo had the highest linear flow in both tested methods, but showed intermediate volumetric flow and cavity filling rates when evaluated using $\mu \mathrm{CT}$, in comparison with the other two materials. MTA Repair HP had the highest volumetric filling using the $\mu \mathrm{CT}$ analysis.

Regarding $\mathrm{pH}$ analysis, Bio-C Pulpo showed the highest alkalinity values during all the tested periods. MTA Repair HP and MTA Angelus showed similar values in the 3-hour and 28-day periods ( $\mathrm{p}>0.05)$, ranging from 7.9 to 8.3. Bio-C Pulpo had the highest volumetric loss (above 9\%) in the $\mu \mathrm{CT}$ analysis, significantly different from the MTA Repair HP and MTA Angelus values $(\mathrm{p}<0.05)$.

The chemical characterization of XRD plots and the SEM/EDS images are shown in Figure 2. XRD analysis detected calcium hydroxide (portlandite) deposition for the hydrated samples of MTA Repair HP and MTA Angelus after 28-day HBSS immersion.

Table 1. Representation of mean and standard deviation values of color change $(\Delta \mathrm{E})$ after 90 days, and lightness $(\mathrm{L})$ at 24 hours, 28 , and 90 days of analysis.

\begin{tabular}{lcccc}
\hline \multirow{2}{*}{ Composition } & Color change & \multicolumn{3}{c}{ Lightness } \\
\cline { 2 - 5 } & $90 \mathrm{~d}$ & $24 \mathrm{~h}$ & $28 \mathrm{~d}$ & $90 \mathrm{~d}$ \\
\hline Negative control & $6.35 \pm 0.19^{\mathrm{a}}$ & $92.33 \pm 0.77^{\mathrm{a}}$ & $90.80 \pm 1.85^{\mathrm{a}}$ & $90.93 \pm 1.55^{\mathrm{a}}$ \\
Bio-C Pulpo & $152.34 \pm 35.41^{\mathrm{b}}$ & $83.33 \pm 0.76^{\mathrm{b}}$ & $94.73 \pm 0.45^{\mathrm{b}}$ & $94.40 \pm 1.30^{\mathrm{b}}$ \\
MTA Repair HP & $90.66 \pm 0.25^{\mathrm{c}}$ & $87.23 \pm 1.20^{\mathrm{c}}$ & $76.10 \pm 0.17^{\mathrm{c}}$ & $90.80 \pm 0.26^{\mathrm{a}}$ \\
MTA Angelus & $74.93 \pm 0.37^{\mathrm{c}}$ & $89.46 \pm 3.23^{\mathrm{c}}$ & $76.26 \pm 6.90^{\mathrm{c}}$ & $81.16 \pm 2.47^{\mathrm{c}}$ \\
Positive control & $289.13 \pm 33.66^{\mathrm{d}}$ & $65.03 \pm 7.78^{\mathrm{d}}$ & $44.33 \pm 0.57^{\mathrm{d}}$ & $36.46 \pm 3.42^{\mathrm{d}}$ \\
\hline
\end{tabular}

Different lowercase letters indicate statistically significant differences $(p<0.05)$. 

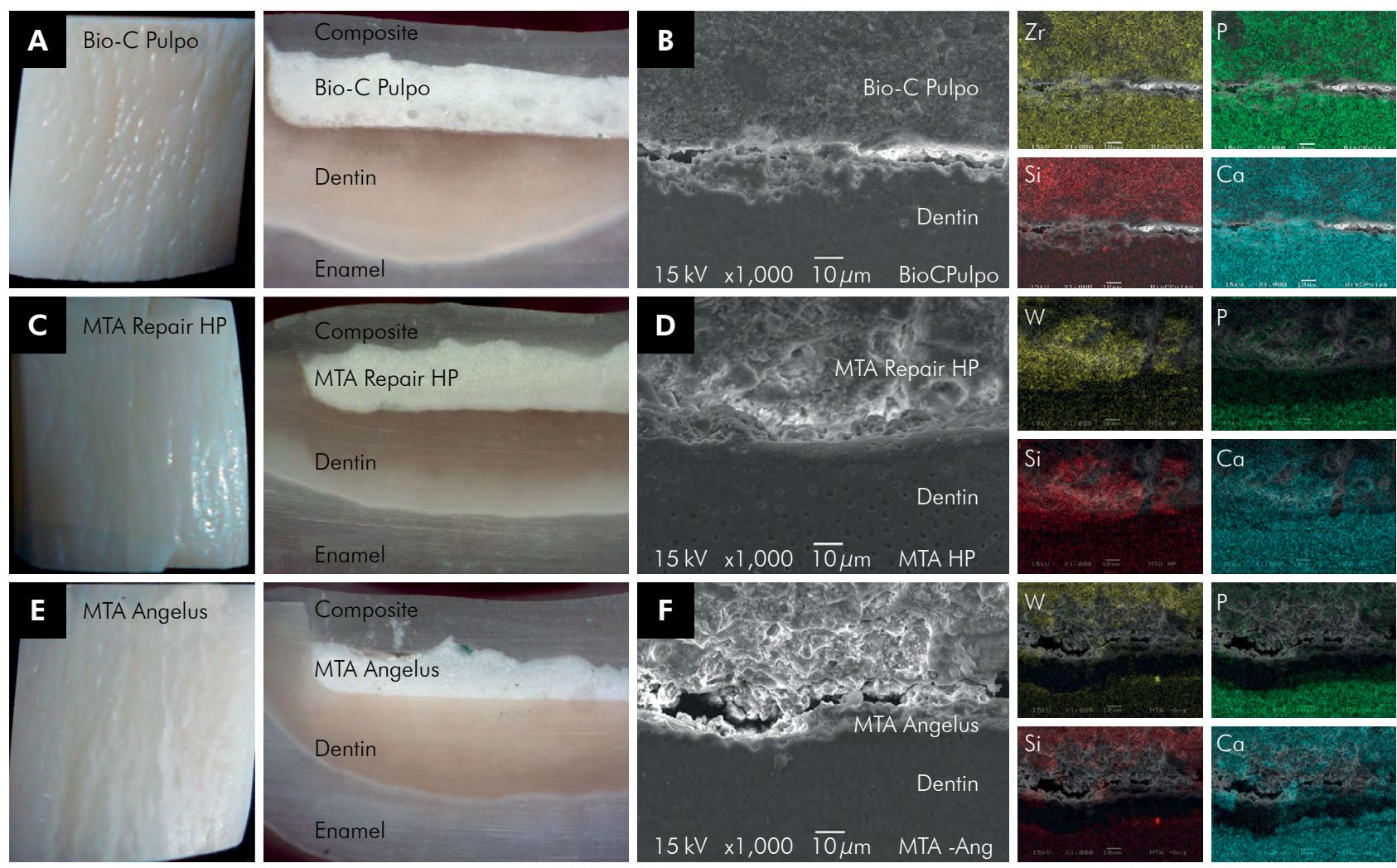

Figure 1. (a, c, e) Representative specimens of bovine teeth filled with cement after 90-day immersion, and stereomicroscopic images of transversal cuts at $2 x$ magnification. $(b, d, f)$ Scanning electron micrographs and overlapped elemental maps of sectioned teeth filled with the tested materials. Calcium (Ca), silicon (Si), and phosphorous (P) were found in all the specimens. In an EDS analysis, phosphorus $(\mathrm{P})$ and zirconium $(\mathrm{Zr})$ ions overlapped in Bio-C Pulpo samples, representing a disadvantage of this analysis when both ions are present. Tungsten (W) ions were present in MTA Repair HP and MTA Angelus cement matrix, and in the adjacent dentin, since these two compositions contain calcium tungstate as a radiopacifier..

Table 2. Representation of mean and standard deviation values of radiopacity, setting time, and flow.

\begin{tabular}{|c|c|c|c|c|c|c|c|}
\hline \multirow{3}{*}{ Material } & \multirow{3}{*}{$\begin{array}{l}\text { Radiopacity } \\
\text { (mm Al) }\end{array}$} & \multicolumn{2}{|c|}{ Setting time (min) } & \multicolumn{4}{|c|}{ Flow } \\
\hline & & & & ISO 6876 & Linear lateral & Volumetric lateral & Volumetric central cavity \\
\hline & & Inıtıal & rinal & $(\mathrm{mm})$ & $(\mathrm{mm})$ & $\left(\mathrm{mm}^{3}\right)\left(\max .4 \mathrm{~mm}^{3}\right)$ & $\left(\mathrm{mm}^{3}\right)\left(\max .2 \mathrm{~mm}^{3}\right)$ \\
\hline Bio-C Pulpo & $6.94 \pm 0.33^{a}$ & $13.97 \pm 0.57^{a}$ & $30.80 \pm 1.57^{a}$ & $11.29 \pm 1.33^{a}$ & $4.95 \pm 1.04^{\circ}$ & $3.05 \pm 0.45^{a}$ & $1.04 \pm 0.19^{a}$ \\
\hline MTA Repair HP & $5.12 \pm 0.31^{b}$ & $4.62 \pm 0.34^{b}$ & $25.02 \pm 0.43^{b}$ & $9.15 \pm 0.16^{\circ}$ & $3.39 \pm 0.93^{a}$ & $3.64 \pm 1.12^{\circ}$ & $1.46 \pm 0.06^{b}$ \\
\hline MTA Angelus & $7.09 \pm 0.18^{a}$ & $30.57 \pm 4.11^{c}$ & $66.83 \pm 0.76 c$ & $9.48 \pm 2.43^{a}$ & $3.53 \pm 0.83^{a}$ & $2.68 \pm 0.52^{a}$ & $0.93 \pm 0.20^{a}$ \\
\hline
\end{tabular}

Different lowercase letters indicate statistically significant differences between the tested materials $(p<0.05)$.

Table 3. Representation of mean and standard deviation values of $\mathrm{pH}$ and volume change.

\begin{tabular}{lcccc}
\hline \multirow{2}{*}{ Composition } & \multicolumn{3}{c}{$\mathrm{pH}$} & Volume change* $^{*}$ \\
\cline { 2 - 5 } & 3 hours & 24 hours & 28 days & (\% after 28 days) \\
\hline Bio-C Pulpo & $9.47 \pm 0.35^{\mathrm{Aa}}$ & $8.58 \pm 0.54^{\mathrm{Ba}}$ & $8.45 \pm 0.97^{\mathrm{ABa}}$ & $-9.53 \pm 2.95^{\mathrm{a}}$ \\
MTA Repair HP & $8.30 \pm 0.10^{\mathrm{Ab}}$ & $8.06 \pm 0.11^{\mathrm{Bb}}$ & $8.30 \pm 0.30^{\mathrm{ABa}}$ & $-3.79 \pm 2.87^{\mathrm{b}}$ \\
MTA Angelus & $7.90 \pm 0.10^{\mathrm{Aab}}$ & $7.93 \pm 0.05^{\mathrm{Aab}}$ & $7.96 \pm 0.15^{\mathrm{Aa}}$ & $-1.45 \pm 0.81^{\mathrm{b}}$ \\
\hline
\end{tabular}

*Volume change in negative values represents volume loss. Different letters in each column indicate statistically significant differences between tested periods (uppercase) and materials (lowercase) $(p<0.05)$. 
Conversely, Bio-CPulpo did not present the portlandite phase, indicating the absence of calcium hydroxide deposition after hydration and HBSS immersion. Analysis of the XRD un-hydrated cement powder showed calcium silicates and radiopacifier peaks of the respective material, as stated by the manufacturers of all the tested materials. SEM/EDS of hydrated cement revealed particles of cement interposed by particles of radiopacifier, and the following chemical elements: calcium (Ca), silicon ( $\mathrm{Si}$ ), and tungsten (W) (radiopacifier) for MTA Repair HP and MTA Angelus; and $\mathrm{Ca}, \mathrm{Si}$, and $\mathrm{Zr}$ (radio-opacifier) for Bio-C Pulpo.

\section{Antimicrobial and Cytotoxicity Analysis}

No inhibition halos were observed for any of the tested materials after the observation period for each microorganism. The discs containing only MTA Repair HP and Bio-C Pulpo liquids also did not inhibit bacterial growth. The spectrophotometer turbidity results after direct contact with $E$. faecalis are represented in Figure 3a. After 24 hours, all the tested materials showed higher levels of turbidity after discounting their solubility, compared to both controls $(p<0.05)$. Bacterial growth was confirmed in the test tubes, and the positive control was confirmed by the aliquots collected simultaneously with the spectrophotometer readings.

MTT cytotoxicity after 24 hours in contact with fibroblast cell culture is shown in Figure 3b. MTA Repair HP showed the highest cytocompatibility, compared with the control group $(\mathrm{p}<0.05)$. MTA Angelus showed intermediate cytocompatibility, with no significant difference compared to the control group ( $p>0.05$ ). Bio-C Pulpo obtained the lowest cell viability among the tested materials, but at a percentage comparable with MTA Angelus ( $p>0.05)$.
A
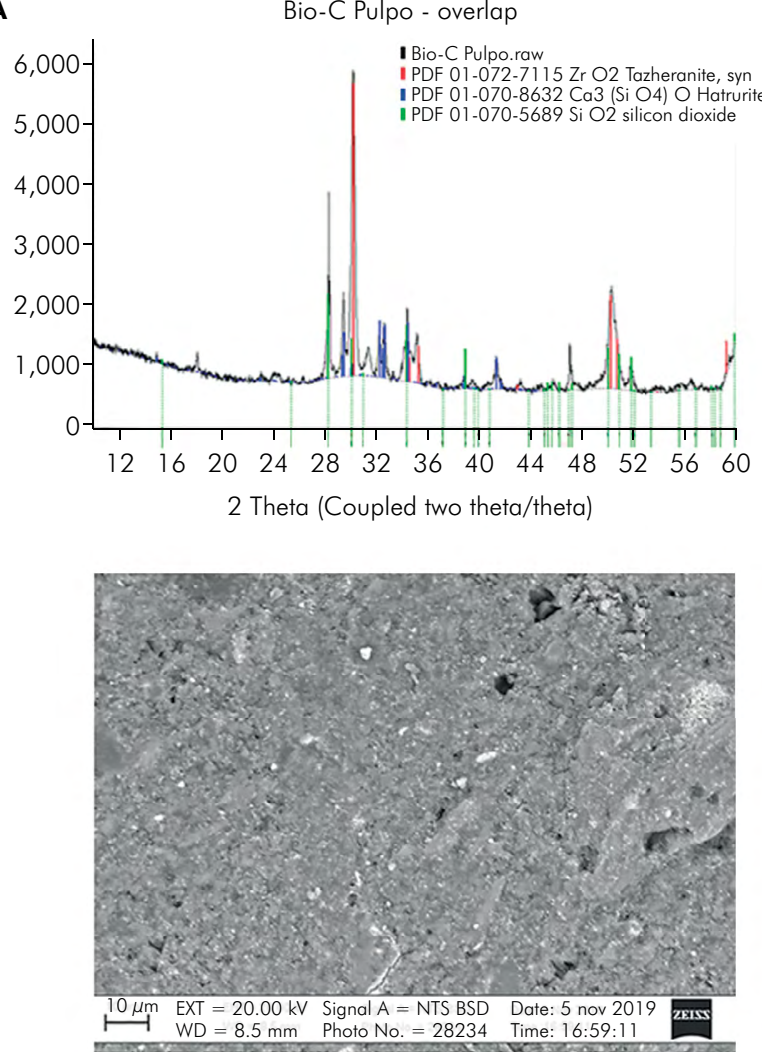

Bio-C Pulpo - 28 days
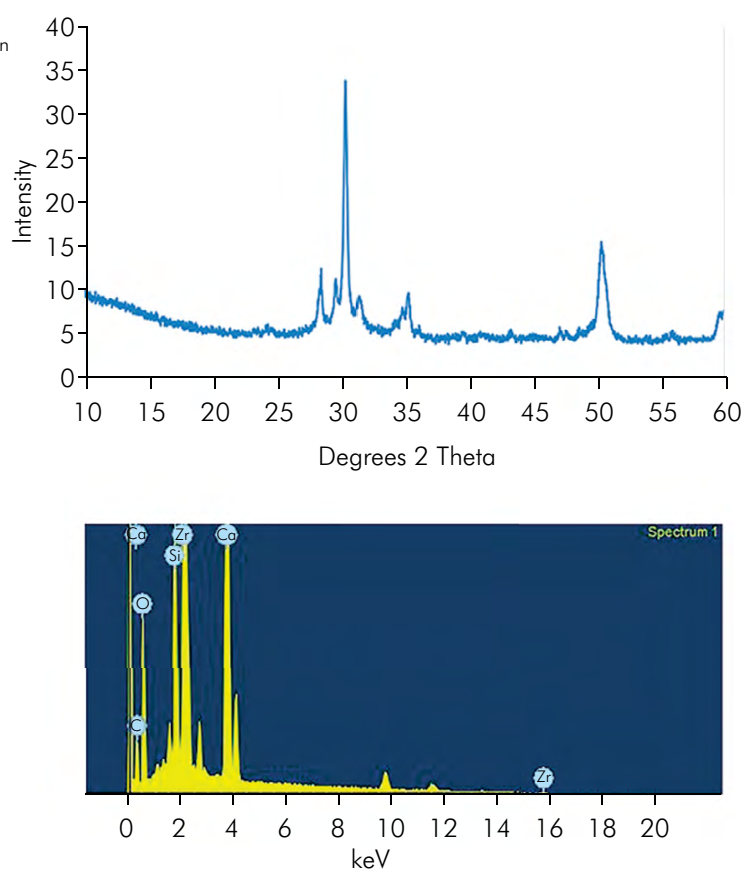

Figure 2. $(a, b, c)$ Representation of X-ray diffraction plots of hydrated cement and overlapped-diffraction of the tested hydraulic calcium silicate-based materials. XRD analysis detected calcium hydroxide (portlandite) deposition for MTA Repair HP and MTA Angelus hydrated samples after 28-day immersion in Hank's Balanced Salt Solution (HBSS). Conversely, Bio-C Pulpo did not present the portlandite phase, indicating the absence of calcium hydroxide deposition after hydration and HBSS immersion. SEM micrographs and EDS plots of hydrated cement revealed particles of cement interposed with small particles of radiopacifier, and with respective element peaks. (Continue) 
B
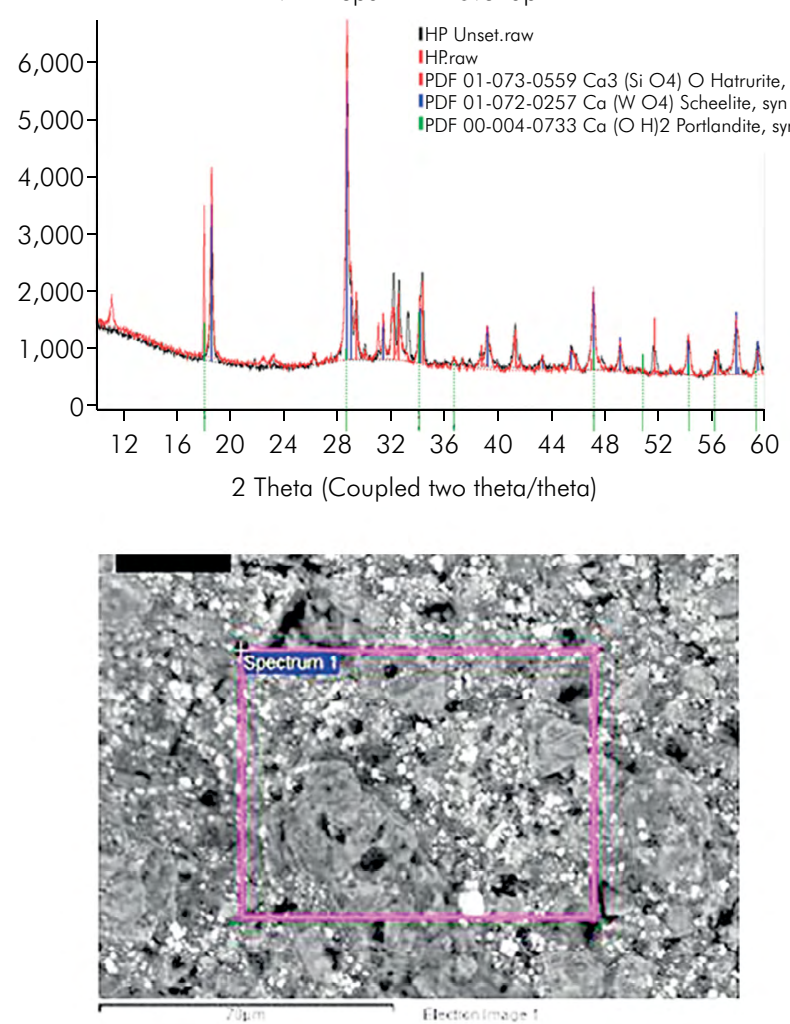

C
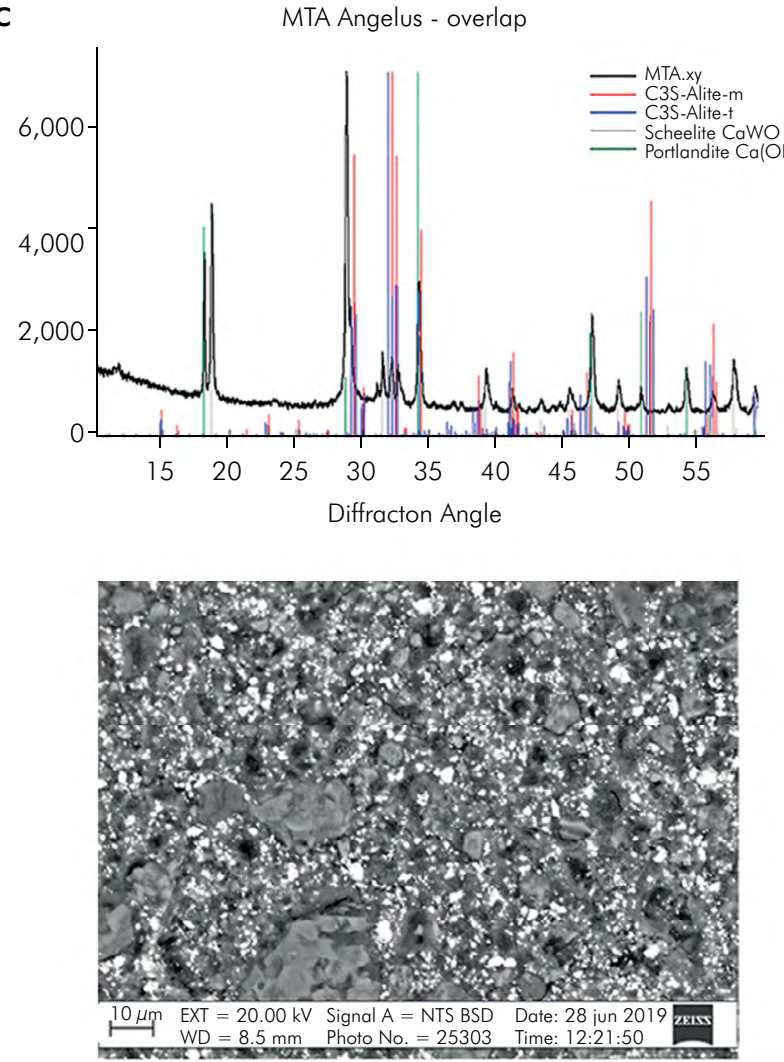

MTA Repair HP - 28 days
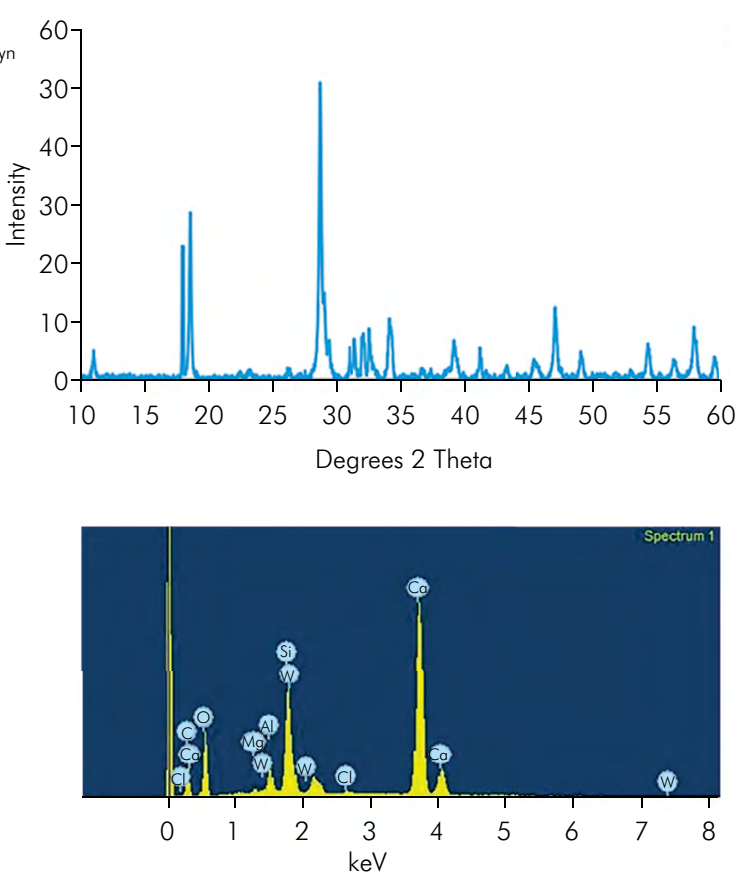

MTA Angelus - 28 days
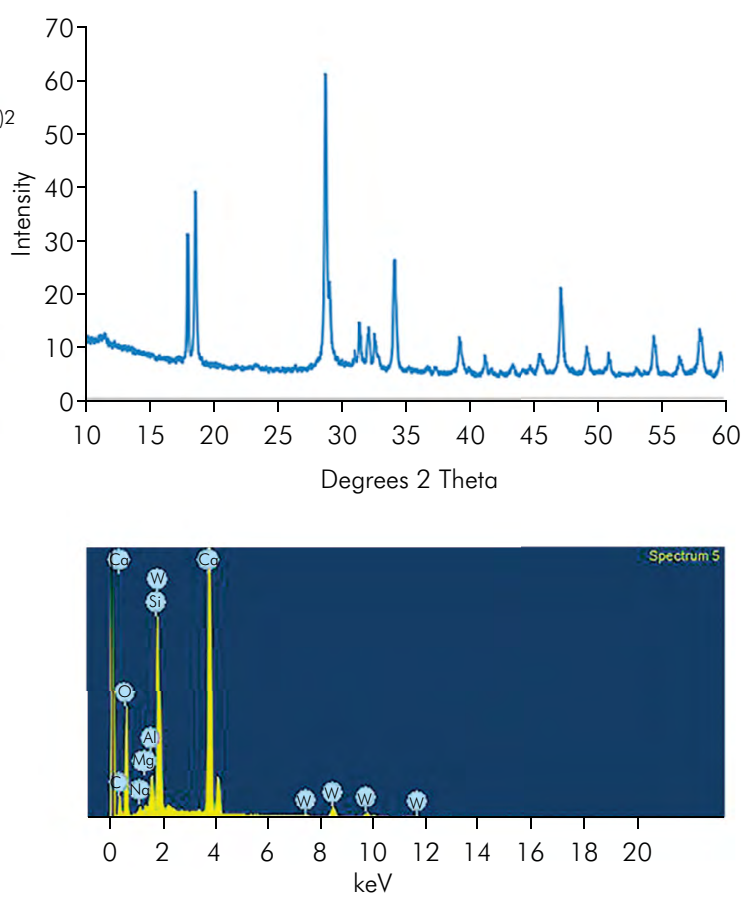

Figure 2. (Continuaton) 

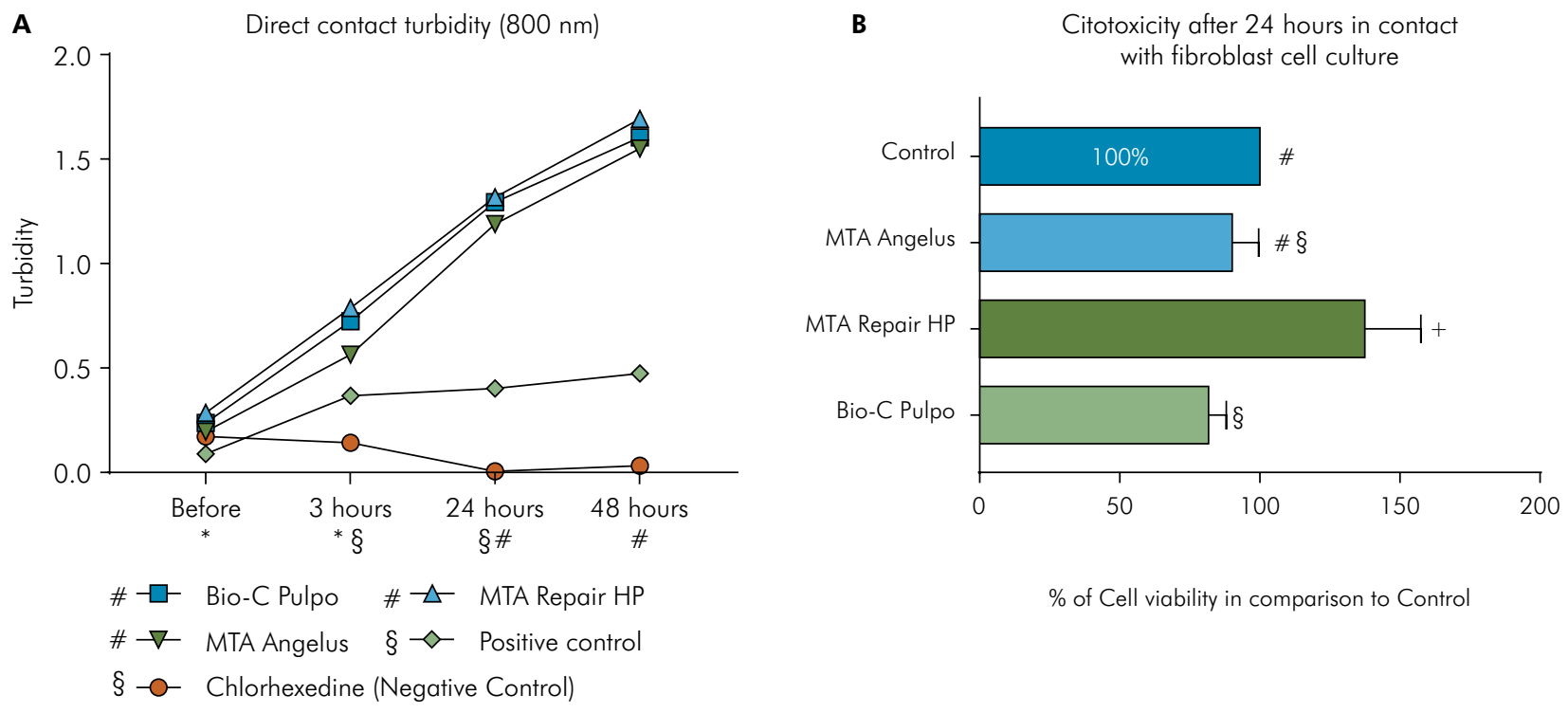

Figure 3. (a) Turbidity in contact with planktonic E. faecalis after 48 hours, for all tested materials. After 48 hours, negative control significantly reduced medium turbidity in comparison with the tested materials, and showed lower turbidity values in comparison with the positive control. (b) Cytotoxicity box-plot in comparison with the control (100\%). MTA Repair HP showed the highest cytocompatibility in comparison with the control group, and Bio-C Pulpo showed the highest cytotoxicity. (\#, * $\left.\S^{*}+\right)$ Different symbols represent statistical differences among each period evaluated or material tested.

\section{Discussion}

This study aimed to evaluate a new modified hydraulic calcium silicate-based pulp capping material, Bio-CPulpo, and assess its physicochemical, biological, and antimicrobial properties, in comparison with MTA Angelus and MTA Repair HP. This material is indicated as a replacement of calcium hydroxide cement in vital pulp procedures. MTA Angelus has had clinical success as pulp capping material. ${ }^{8}$ MTA Repair HP is similar, but its handling was improved by the addition of polyvinylpyrrolidone to the liquid to offset this main shortcoming attributed to MTA Angelus.

Testing used a holistic approach; thereby requiring a wide range of tests to be used, including physicochemical and both biological and microbiological assessment. ${ }^{18}$ A range of physicochemical properties was assessed, including color alteration in contact with dentin and chemical characterization, two basic antimicrobial tests, and the MTT biological test of the three tested compositions. Long-term antimicrobial challenges constantly occur after restorative procedures, and may cause treatment failures. This warranted the inclusion of two different bacterial strains (E. faecalis and $P$. gingivalis) in the antimicrobial evaluation, ${ }^{19,20}$ along with the $\mu \mathrm{CT}$ volume change analysis, since a long-term sealed interface would prevent microbial infections and guarantee clinical success. E. faecalis is a facultative Gram-positive bacterium, which has been associated with several oral diseases including dental caries, endodontic infections, apical periodontitis, peri-implantitis, and endodontic-periodontal diseases. ${ }^{21,22}$ For this reason, it is used in several in vitro studies to test the antimicrobial properties of dental materials, and the efficacy of the endodontic procedures, including pulp capping procedures. ${ }^{23}$ $P$. gingivalis are black-pigmented gram-negative anaerobic bacteria relatively common in infected root canals and endodontic abscesses. They produce a substantial array of putative virulence factors, and their presence is often accompanied by swelling and periodontal diseases. ${ }^{24}$ These two bacterial strains were included in the present study, owing to their different metabolism and culture peculiarities.

The absence of a specific ISO standard for hydraulic calcium silicate-based materials warrants the inclusion of previously reported methods in the general selection of tests, and the use of the ISO 6876:2012 standard (for endodontic sealers) to evaluate 
new compositions s, $^{7,11,12,18,25,26,27}$ such as Bio-C Pulpo. The inclusion of MTT cell culture testing with fibroblasts was used as a preliminary test for subcutaneous animal biocompatibility, considering the principles of the 3Rs (Replacement, Reduction, and Refinement) in research. ${ }^{28}$ The data obtained from primary fibroblasts - even if not derived from dental pulp - are more relevant and reflective of the in vivo environment, than the data produced from immortalized cells. Primary cells retain morphological and functional characteristics seen in vivo. ${ }^{29}$ Furthermore, both pulp and periodontal ligament have an embryonic mesenchymal origin and rely on fibroblasts that will form the principal periodontal ligament fibers, and pulpal extracellular matrix, ${ }^{30}$ thus highlighting the relevance of our cell line of choice.

Once pulp capping materials are used in the coronal tooth portion, aesthetics is an aspect to be considered in long-term procedures. ${ }^{31}$ In the present study, the color assessment of the materials using the CIELab formula in contact with dentin used a previously reported method that evaluated MTA Angelus before the manufacturer replaced the bismuth oxide $^{7}$ with calcium tungstate in this radiopacifier. The use of the CIELab formula was preferred in the present study to allow comparison with previous studies ${ }^{7,26}$ that used this method of analysis. The presence of bismuth oxide reported in that study resulted in considerably low $\mathrm{L}$ values and dentin staining in MTA Angelus samples. In the present study evaluating a recent MTA Angelus batch (\#45293), the radiopacifier was changed to calcium tungstate, and this material did not show significant dentin staining when compared with the positive control samples. The overlap of $\mathrm{Zr}$ and $\mathrm{P}$ ions peaks hinders the material/dentin interface EDS analysis in Bio-C Pulpo samples. This EDS limitation was previously reported for these two ions. ${ }^{32} \mathrm{~W}$-ions were present in adjacent dentin mappings for MTA Angelus and MTA Repair HP samples, but no significant color alterations were detected, owing to this migration. compared with the negative control. Future studies considering color differences perceived clinically may consider using the CIEDE2000 formula ${ }^{33}$ associated with the CIELab used in the present study to perform further comparisons.
Radiopacity is an essential material characteristic, since it allows clinical follow-up using radiographic or tomographic exams. ${ }^{25}$ All the materials showed average radiopacity values above $5 \mathrm{~mm} \mathrm{Al}$, thus complying with the ISO 6876:2012 requirement. The use of alternative radiopacifiers, such as zirconium oxide and calcium tungstate (replacing bismuth oxide) resulted in acceptable aesthetics. Another critical issue to be considered is the influence of the radiopacifier for calcium silicate hydration. ${ }^{34} \mathrm{~A}$ previous study investigated the rheological water demand when different radiopacifiers are added to tricalcium silicate. ${ }^{35}$ The authors concluded that $30 \%$ of the zirconium oxide replacing tricalcium silicate did not affect the amount of water needed for its hydration. In the present study, the zirconium oxide present in the Bio-C Pulpo composition provided adequate radiopacity.

Material consistency during working time is a crucial property to be considered, since insertion in the cavity during clinical application is required for operative success. ${ }^{36}$ MTA Repair HP had the fastest setting time (about five minutes), which is half of the time required for Bio-C Pulpo and six times faster than MTA Angelus. A short setting time, like that obtained in the present study for MTA Repair HP, is needed for materials used as pulp capping material. A previous study ${ }^{9}$ reported a higher setting time for MTA Repair HP, but the authors used a different needle weight for the evaluation, and considered only the initial setting time of this material. Bio-C Pulpo formulation did not result in a setting time comparable to that obtained for MTA Repair HP in the conditions of the present study.

Freshly mixed hydraulic materials should ideally present a consistency that facilitates their insertion in cavities to ensure their flow and sealing. In this study, two methods were used: ISO-6876:2012, which is normative for root canal sealer evaluation, and a $\mu$ CT-based method. ${ }^{13}$ Bio-C Pulpo had the highest linear flow, which can be attributed to its powder/ water ratio, and to the plasticizing additives (not yet disclosed by the manufacturer) added to its liquid composition. Regarding MTA Repair HP, this material showed the highest volumetric filling considering the $\mu \mathrm{CT}$-based method. No previous studies have reported 
the volumetric flow of Bio-C Pulpo, MTA Repair HP, and MTA Angelus. ISO 6786:2012 is recommended for sealers used in endodontics, but different indications and consistencies are observed in hydraulic calcium silicate-based materials; consequently, a specific standard is required to guide the development of future new compositions.

An alkaline $\mathrm{pH}$ solution is an indication of calcium ion release in an aqueous environment. ${ }^{37}$ Bio-C Pulpo demonstrated the highest alkalinity average values during all of the tested periods. This could partially be explained by the calcium hydroxide present in its powder formulation before hydration, and the significant material volume loss above $9 \%$ after 28 days immersion observed using the $\mu \mathrm{CT}$-based method to evaluate this material, which was significantly higher than the volume loss observed for MTA Repair HP and MTA Angelus. Bio-C Pulpo lost a higher volume, compared to the other materials, but this material is indicated only as pulp capping material, and must therefore be contained inside a dentin cavity that is immediately sealed by composite materials.

Cement XRD analysis is a method that does not consider elements individually, but in combination. ${ }^{38}$ Calcium hydroxide (portlandite) deposition after the hydration of hydraulic calcium silicate-based materials is a very important aspect that justified its chemical characterization after 28-day HBSS-immersion using XRD in the present study. Bio-CPulpo did not undergo the portlandite phase in the XRD peaks in the present study (Figure 2). This critical material drawback was previously, ${ }^{11}$ and the absence of calcium hydroxide deposition was associated with the presence of silicon oxide in the Bio-C Pulpo powder, used as an additive to strengthen the cement matrix. This previous study also reported high alkaline $\mathrm{pH}$ values for Bio-C Pulpo, corroborating the results observed in the present study. The MTA Repair HP and MTA Angelus hydrated samples showed detectable calcium hydroxide (portlandite). A previous study ${ }^{39}$ reported the MTA Angelus calcium hydroxide deposition after hydration using XRD. The radiopacifier was still bismuth oxide. The present study detected calcium hydroxide deposition in MTA Angelus, with an alternative radiopacifier (calcium tungstate), and similar deposition observed for MTA Repair HP.
Antimicrobial activity is an expected characteristic of hydraulic endodontic cement, since these materials are used in contaminated clinical sites..$^{40} \mathrm{In}$ the present study, neither formulation (MTA Angelus nor MTA Repair HP) satisfactorily inhibited bacterial growth, compared with direct contact with chlorhexidine $2 \%$ in both methods. Solubility halos were observed over agar, showing that this test seems inadequate because of possible misleading interpretation. A previous study reported similar observations testing hydraulic endodontic materials in contact with agar. ${ }^{41}$ As for planktonic E. faecalis, all tested materials showed significantly higher values of turbidity, and an apparent up-regulation of bacterial growth when the undiluted material was directly in contact with the E. faecalis in the BHI broth. This microorganism has caused endodontic treatment to fail, owing to high resistance to endodontic irrigants and medicaments, ${ }^{42}$ and to its ability to survive in an environment of limited availability of nutrients and minimal commensality with other bacteria. It is associated with well-known mechanisms of virulence and resistance, which hinder its eradication from infected dentin. ${ }^{43}$ This partially explains the antimicrobial results of the present study regarding calcium silicate-based materials. Further studies with multispecies biofilms and live/dead bacterial quantification are undoubtedly necessary to clarify these findings. During the clinical use of hydraulic calcium silicate-based cement, its application site must be previously disinfected, since the materials per se do not possess robust antimicrobial efficacy.

In vitro cytotoxicity assays, such as MTT used in the present study, are preliminary to animal testing, and essential to understand the behavior of new compositions ${ }^{44}$ such as Bio-CPulpo. After 24 hours, this material exhibited a lower percentage of cell viability in comparison with the other tested materials. This can be attributed to the higher solubility and high $\mathrm{pH}$ values obtained for this material in the same period of analysis as MTA Angelus and MTA Repair HP. Direct contact with pulp tissue occurs during direct pulp capping procedures; therefore, it is expected that this type of material, indicated for pulp capping, would have cytocompatibility. MTA Repair HP and MTA Angelus obtained better cytocompatibility results than 
Bio-C Pulpo in the present study. A previous study ${ }^{8}$ reported $96 \%$ success rates after a 3 -year follow-up for direct pulp capping or pulpotomy procedures using MTA Angelus. Another previous study ${ }^{45}$ evaluated Bio-C Pulpo biocompatibility, and concluded that this material performed similar to MTA Angelus after contact with Wistar rat connective tissue. MTA Repair HP was considered similar to MTA Angelus in a previous study, considering that in vitro cytotoxicity was tested in direct contact with primary-osteoblast cell culture. ${ }^{9}$ Nonetheless, given that none of the tested materials have additional chemical components or molecular agents that stand out as being known to induce mitochondrial biogenesis or hyperactivation, MTT is a reasonable first approach for cytotoxicity/cell viability evaluation. ${ }^{46,47}$ A more robust multiparametric evaluation of the biological effects of these materials should be the aim of future investigations, using different types of cells and biocompatibility studies, in order to compare the results of these materials with well-researched material such as MTA Angelus.

Therefore, the tested hypothesis that the additives used in the new Bio-C Pulpo composition do not interfere in its properties was rejected, since the properties of volume loss and cytotoxicity were significantly higher in Bio-C Pulpo than in MTA Repair HP or MTA Angelus. The absence of calcium hydroxide deposition after hydration is a significant concern, since this composition is indicated for pulp capping procedures.

\section{Conclusion}

Bio-C Pulpo showed physical properties comparable to the other tested materials; however, it did not precipitate calcium hydroxide after hydration. Therefore, its indication as a pulp capping material must be further investigated along with its biocompatibility before clinical use. MTA Angelus, with calcium tungstate as a radiopacifier, does not stain dentin, and has properties comparable to MTA Repair HP, which has been improved in regard to its handling, thus positively altering its flow properties in comparison with MTA Angelus.

\section{Acknowledgments}

This study was supported by the State of São Paulo Research Foundation (FAPESP 2017/ 05096-7, 2017/18413-0, 2018/16722-9, 2018/06515-6). The authors wish to thank MSc. Maicon Ricardo Zieberg Passini and MSc. Adriano Luis Martins for their technical assistance. The authors would like to acknowledge Prof. Josette Camilleri for her expertise and assistance in the characterization test.

\section{References}

1. Biørndal L, Simon S, Tomson PL, Duncan HF. Management of deep caries and the exposed pulp. Int Endod J. 2019 Jul;52(7):949-73. https://doi.org/10.1111/iej.13128

2. Duncan HF, Galler KM, Tomson PL, Simon S, El-Karim I, Kundzina R, et al. European Society of Endodontology position statement: management of deep caries and the exposed pulp. Int Endod J. 2019 Jul;52(7):923-34. https://doi.org/10.1111/iej.13080

3. Camilleri J. Mineral trioxide aggregate : present and future developments. Endod Topics. 2015;(2):31-46. https://doi.org/10.1111/etp.12073

4. Yoshihara K, Nagaoka N, Okihara T, Irie M, Matsukawa A, Pedano MS, et al. Development of self-adhesive pulp-capping agents containing a novel hydrophilic and highly polymerizable acrylamide monomer. J Mater Chem B Mater Biol Med. 2020 Jun;8(24):5320-9. https://doi.org/10.1039/D0TB00079E

5. Camilleri J, Montesin FE, Di Silvio L, Pitt Ford TR. The chemical constitution and biocompatibility of accelerated Portland cement for endodontic use. Int Endod J. 2005 Nov;38(11):834-42. https://doi.org/10.1111/j.1365-2591.2005.01028.x

6. Galarça AD, Rosa WL, Silva TM, Lima GS, Carreño NL, Pereira TM, et al. Physical and Biological Properties of a High-Plasticity Tricalcium Silicate Cement. BioMed Res Int. 2018 Nov;2018:8063262. https://doi.org/10.1155/2018/8063262

7. Marciano MA, Costa RM, Camilleri J, Mondelli RF, Guimarães BM, Duarte MA. Assessment of color stability of white mineral trioxide aggregate angelus and bismuth oxide in contact with tooth structure. J Endod. 2014 Aug;40(8):1235-40. https://doi.org/10.1016/i.joen.2014.01.044 
8. Awawdeh L, Al-Qudah A, Hamouri H, Chakra RJ. Outcomes of Vital Pulp Therapy Using Mineral Trioxide Aggregate or Biodentine: A Prospective Randomized Clinical Trial. J Endod. 2018 Nov;44(11):1603-9. https://doi.org/10.1016/i.joen.2018.08.004

9. Ferreira CM, Sassone LM, Gonçalves AS, Carvalho JJ, Tomás-Catalá CJ, García-Bernal D, et al. Physicochemical, cytotoxicity and in vivo biocompatibility of a high-plasticity calcium-silicate based material. Sci Rep. 2019 Mar;9(1):3933. https://doi.org/10.1038/s41598-019-40365-4

10. Islam I, Chng HK, Yap AU. Comparison of the physical and mechanical properties of MTA and portland cement. J Endod. 2006 Mar;32(3):193-7. https://doi.org/10.1016/i.joen.2005.10.043

11. Koutroulis A, Kuehne SA, Cooper PR, Camilleri J. The role of calcium ion release on biocompatibility and antimicrobial properties of hydraulic cements. Sci Rep. 2019 Dec;9(1):19019. https://doi.org/10.1038/s41598-019-55288-3

12. Cavenago BC, Pereira TC, Duarte MA, Ordinola-Zapata R, Marciano MA, Bramante CM, et al. Influence of powder-to-water ratio on radiopacity, setting time, $\mathrm{pH}$, calcium ion release and a micro-CT volumetric solubility of white mineral trioxide aggregate. Int Endod J. 2014 Feb;47(2):120-6. https://doi.org/10.1111/iej.12120

13. Tanomaru-Filho M, Torres FF, Bosso-Martelo R, Chávez-Andrade GM, Bonetti-Filho I, Guerreiro-Tanomaru JM. A novel model for evaluating the flow of endodontic materials using micro-computed tomography. J Endod. 2017 May;43(5):796-800. https://doi.org/10.1016/i.joen.2016.12.002

14. Camilleri J, Montesin FE, Papaioannou S, McDonald F, Pitt Ford TR. Biocompatibility of two commercial forms of mineral trioxide aggregate. Int Endod J. 2004 Oct;37(10):699-704. https://doi.org/10.1111/j.1365-2591.2004.00859.x

15. Marciano MA, Duarte MA, Camilleri J. Calcium silicate-based sealers: assessment of physicochemical properties, porosity and hydration. Dent Mater. 2016 Feb;32(2):e30-40. https://doi.org/10.1016/i.dental.2015.11.008

16. Gomes BP. Pedroso JA, Jacinto RC, Vianna ME, Ferraz CCR, Zaia AA, et al. In vitro evaluation of the antimicrobial activity of five root canal sealers. Braz Dent J. 2004;15(1):30-35. https://doi.org/10.1590/S0103-64402004000100006

17. Silva EJ, Senna PM, De-Deus G, Zaia AA. Cytocompatibility of Biodentine using a three-dimensional cell culture model. Int Endod J. 2016 Jun;49(6):574-80. https://doi.org/10.1111/iej.12485

18. Camilleri J, Arias Moliz T, Bettencourt A, Costa J, Martins F, Rabadijeva D, et al. Standardization of antimicrobial testing of dental devices. Dent Mater. 2020 Mar;36(3):e59-73. https://doi.org/10.1016/j.dental.2019.12.006

19. Gomes BP F A, Pinheiro ET, Gadê-Neto CR, Sousa EL, Ferraz CC, Zaia AA, et al. Microbiological examination of infected dental root canals. Oral Microbiol Immunol. 2004 Apr;19(2):71-6. https://doi.org/10.1046/i.0902-0055.2003.00116.x

20. Koruyucu M, Topcuoglu N, Tuna EB, Ozel S, Gencay K, Kulekci G, et al. An assessment of antibacterial activity of three pulp capping materials on Enterococcus faecalis by a direct contact test: an in vitro study. Eur J Dent. 2015 Apr-Jun;9(2):240-5. https://doi.org/10.4103/1305-7456.156837

21. Gomes BP, Berber VB, Kokaras AS, Chen T, Paster BJ. Microbiomes of Endodontic-Periodontal Lesions before and after Chemomechanical Preparation. J Endod. 2015 Dec;41(12):1975-84. https://doi.org/10.1016/j.joen.2015.08.022

22. Kouidhi B, Zmantar T, Mahdouani K, Hentati H, Bakhrouf A. Antibiotic resistance and adhesion properties of oral Enterococci associated to dental caries. BMC Microbiol. 2011 Jun;11(1):155. https://doi.org/10.1186/1471-2180-11-155

23. Yalcin M, Arslan U, Dundar A. Evaluation of antibacterial effects of pulp capping agents with direct contact test method. Eur J Dent. 2014 Jan;8(1):95-9. https://doi.org/10.4103/1305-7456.126256

24. Gomes BP, Jacinto RC, Pinheiro ET, Sousa EL, Zaia AA, Ferraz CC, et al. Porphyromonas gingivalis, Porphyromonas endodontalis, Prevotella intermedia and Prevotella nigrescens in endodontic lesions detected by culture and by PCR. Oral Microbiol Immunol. 2005 Aug;20(4):211-5. https://doi.org/10.1111/j.1399-302X.2005.00214.x

25. Duarte MAH, El Kadre GDO, Vivan RR, Tanomaru JMG, Tanomaru Filho M, Moraes IG. Radiopacity of portland cement associated with different radiopacifying agents. J Endod. 2009 May;35(5):737-40. https://doi.org/10.1016/i.joen.2009.02.006

26. Pelepenko LE, Saavedra F, Antunes TB, Bombarda GF, Gomes BPFA, Zaia AA, et al. Physicochemical, antimicrobial, and biological properties of White-MTAFlow. Clin Oral Investig. 2021;25:663-72: https://doi.org/10.1007/s00784-020-03543-7

27. Pelepenko LE, Saavedra F, Bombarda GF, Gomes BP, DE-Jesus-Soares A, Zaia AA, et al. Dental discoloration caused by Grey-MTAFlow cement: analysis of its physicochemical, biological and antimicrobial properties. J Appl Oral Sci. 2020;28:e20200269. https://doi.org/10.1590/1678-7757-2020-0269

28. Flecknell P. Replacement, reduction and refinement. Altex. 2002;19(2):73-8.

29. Pan C, Kumar C, Bohl S, Klingmueller U, Mann M. Comparative proteomic phenotyping of cell lines and primary cells to assess preservation of cell type-specific functions. Mol Cell Proteomics. 2009 Mar;8(3):443-50. https://doi.org/10.1074/mcp.M800258-MCP200

30. Huang GT, Gronthos S, Shi S. Mesenchymal stem cells derived from dental tissues vs. those from other sources: their biology and role in regenerative medicine. J Dent Res. 2009 Sep;88(9):792-806. https://doi.org/10.1177/0022034509340867

31. Camilleri J, Borg J, Damidot D, et al. Colour and chemical stability of bismuth oxide in dental materials with solutions used in routine clinical practice. PLoS One. 2020;15(11):e0240634. https://doi.org/10.1371/journal.pone.0240634 
32. Moinzadeh AT, Aznar Portoles C, Schembri Wismayer P, Camilleri J. Bioactivity potential of endo sequence BC RRM putty. J Endod. 2016 Apr;42(4):615-21. https://doi.org/10.1016/i.joen.2015.12.004

33. Gómez-Polo C, Portillo Muñoz M, Lorenzo Luengo MC, Vicente P, Galindo P, Martín Casado AM. Comparison of the CIELab and CIEDE2000 color difference formulas. J Prosthet Dent. 2016 Jan;115(1):65-70. https://doi.org/10.1016/i.prosdent.2015.07.001

34. Camilleri J. Hydration mechanisms of mineral trioxide aggregate. Int Endod J. 2007 Jun;40(6):462-70. https://doi.org/10.1111/j.1365-2591.2007.01248.x

35. Koutroulis A, Batchelor H, Kuehne SA, Cooper PR, Camilleri J. Investigation of the effect of the water to powder ratio on hydraulic cement properties. Dent Mater. 2019 Aug;35(8):1146-54. https://doi.org/10.1016/i.dental.2019.05.011

36. Bortoluzzi EA, Broon NJ, Bramante CM, Felippe WT, Tanomaru Filho M, Esberard RM. The influence of calcium chloride on the setting time, solubility, disintegration, and $\mathrm{pH}$ of mineral trioxide aggregate and white Portland cement with a radiopacifier. J Endod. 2009 Apr;35(4):550-4. https://doi.org/10.1016/j.joen.2008.12.018

37. Duarte MA, Demarchi AC, Yamashita JC, Kuga MC, Fraga SC. pH and calcium ion release of 2 root-end filling materials. Oral Surg Oral Med Oral Pathol Oral Radiol Endod. 2003 Mar;95(3):345-7. https://doi.org/10.1067/moe.2003.12

38. Camilleri J. Characterization of hydration products of mineral trioxide aggregate. Int Endod J. 2008 May;41(5):408-17. https://doi.org/10.1111/i.1365-2591.2007.01370.x

39. Marciano MA, Camilleri J, Costa RM, Matsumoto MA, Guimarães BM, Duarte MA. Zinc Oxide Inhibits Dental Discoloration Caused by White Mineral Trioxide Aggregate Angelus. J Endod. 2017 Jun;43(6):1001-7. https://doi.org/10.1016/i.joen.2017.01.029

40. Farrugia C, Baca P, Camilleri J, Arias Moliz MT. Antimicrobial activity of ProRoot MTA in contact with blood. Sci Rep. 2017 Jan;7(1):41359. https://doi.org/10.1038/srep41359

41. Farrugia C, Haider J, Camilleri L, Camilleri J. Clinical relevance of antimicrobial testing results for dental restorative materials. J Appl Biomater Funct Mater. 2017;15(2):e153-61. https://doi.org/10.5301/jabfm.5000337

42. Gomes BP, Pinheiro ET, Sousa EL, Jacinto RC, Zaia AA, Ferraz CC, et al. Enterococcus faecalis in dental root canals detected by culture and by polymerase chain reaction analysis. Oral Surg Oral Med Oral Pathol Oral Radiol Endod. 2006 Aug;102(2):247-53. https://doi.org/10.1016/j.tripleo.2005.11.031

43. Gomes BP, Herrera DR. Etiologic role of root canal infection in apical periodontitis and its relationship with clinical symptomatology. Braz Oral Res. 2018 Oct;32 suppl 1:e69. https://doi.org/10.1590/1807-3107bor-2018.vol32.0069

44. Li W, Zhou J, Xu Y. Study of the in vitro cytotoxicity testing of medical devices. Biomed Rep. 2015 Sep;3(5):617-20. https://doi.org/10.3892/br.2015.481

45. Cosme-Silva L, Benetti F, Dal-Fabbro R, Gomes Filho JE, Sakai VT, Cintra LT, et al. Biocompatibility and biomineralization ability of Bio-C Pulpecto. A histological and immunohistochemical study. Int J Paediatr Dent. 2019 May;29(3):352-60. https://doi.org/10.1111/ipd.12464

46. Rai Y, Pathak R, Kumari N, Sah DK, Pandey S, Kalra N, et al. Mitochondrial biogenesis and metabolic hyperactivation limits the application of MTT assay in the estimation of radiation induced growth inhibition. Sci Rep. 2018 Jan;8(1):1531. https://doi.org/10.1038/s41598-018-19930-w

47. Fonseca DA, Paula AB, Marto CM, Coelho A, Paulo S, Martinho JP, et al. Biocompatibility of root canal sealers: a systematic review of in vitro and in vivo studies. Materials (Basel). 2019 Dec;12(24):4113. https://doi.org/10.3390/ma12244113 